\title{
El Coloso elocuente (1747-1748). Un certamen poético del ultrabarroco novohispano
}

\section{The Coloso elocuente (1747-1748): An Ultra-Baroque Poetic \\ Contest from the Vice-Royal Mexico}

JORGE GUTIÉRREZ REYNA [jorge_gtz_reyna@hotmail.com]

Universidad Nacional Autónoma de México, México

Universidad del Claustro de Sor Juana, México

\section{RESUMEN}

El presente artículo busca llamar la atención sobre un certamen realizado por la Universidad de México en 1747 para celebrar la exaltación al trono de Fernando VI, cuya descripción se imprimió un año después bajo el título de Coloso elocuente, y se debe a la pluma de Pedro José Ramírez de Arizpe. A partir de un análisis de los festejos realizados alrededor del certamen, del tema del mismo y de las exigencias específicas de sus categorías, el artículo propone una interpretación y comentario de algunos de los poemas participantes, en particular, de las décimas acrósticas escritas por Mariana Navarro. Con base en lo anterior, el presente estudio sostiene que el certamen descrito en el Coloso elocuente es fundamental para comprender, por un lado, uno de los festejos más ostentosos de la historia cultural del virreinato y, por otro, para vislumbrar ese barroco intensificado que se extendió por buena parte del siglo XVIII novohispano y que podríamos tildar de ultrabarroco.

\section{PALABRAS CLAVE}

Coloso elocuente; Pedro José Ramírez de Arizpe; certamen poético; Mariana Navarro; poesía novohispana

\begin{abstract}
This article intends to highlight the importance of a poetic contest organized by the University of Mexico in 1747 in order to celebrate the coronation of Fernando VI. The contest was described by Pedro José Ramírez de Arizpe and published one year later with the title Coloso elocuente. Based on an analysis of the festivities of which this contest formed a part, as well as the poetics exigencies of the contest itself, I propose an interpretation of some of the winning compositions, particularly an acrostic poem by Mariana Navarro. This study argues that the contest described in the Coloso elocuente is fundamental to the comprehension of one of the most ostentatious celebrations in the cultural history of vice regal Mexico. Likewise, it offers a fascinating glimpse into the ultra-baroque aesthetic tendencies that characterized the $18^{\text {th }}$ Century New Spain poetry.
\end{abstract}

\section{KEYWORDS}

Coloso elocuente; Pedro José Ramírez de Arizpe; poetic contest; Mariana Navarro; Mexican colonial poetry

RECIBIDO 2018-04-20; ACEPTADO 2018-06-02 
La labor del novohispanista en bibliotecas y polvorientos archivos tiene algo de arqueológica. Provistas las manos de guantes y cubiertas la boca y la nariz, el investigador pasa horas desenterrando cierta literatura que no siempre resulta emocionante. Tal como el arqueólogo restos de vasijas de barro o fragmentos de hueso, el novohispanista con frecuencia halla farragosa prosa en los sermones, tediosos poemas a algún mandatario grisáceo o ristras de arduas citas en latín. Todo contribuye, por supuesto, al conocimiento de la época y suscita su debido interés pero no se puede negar que a veces pueden llegar a encontrarse objetos fascinantes: un collar de lapislázuli, una dorada máscara mortuoria. Hace algunos años, al dar vuelta a unas páginas amarillentas, cuatro planetas anillados que parecen girar sobre la página me salieron al encuentro (Fig. 1):

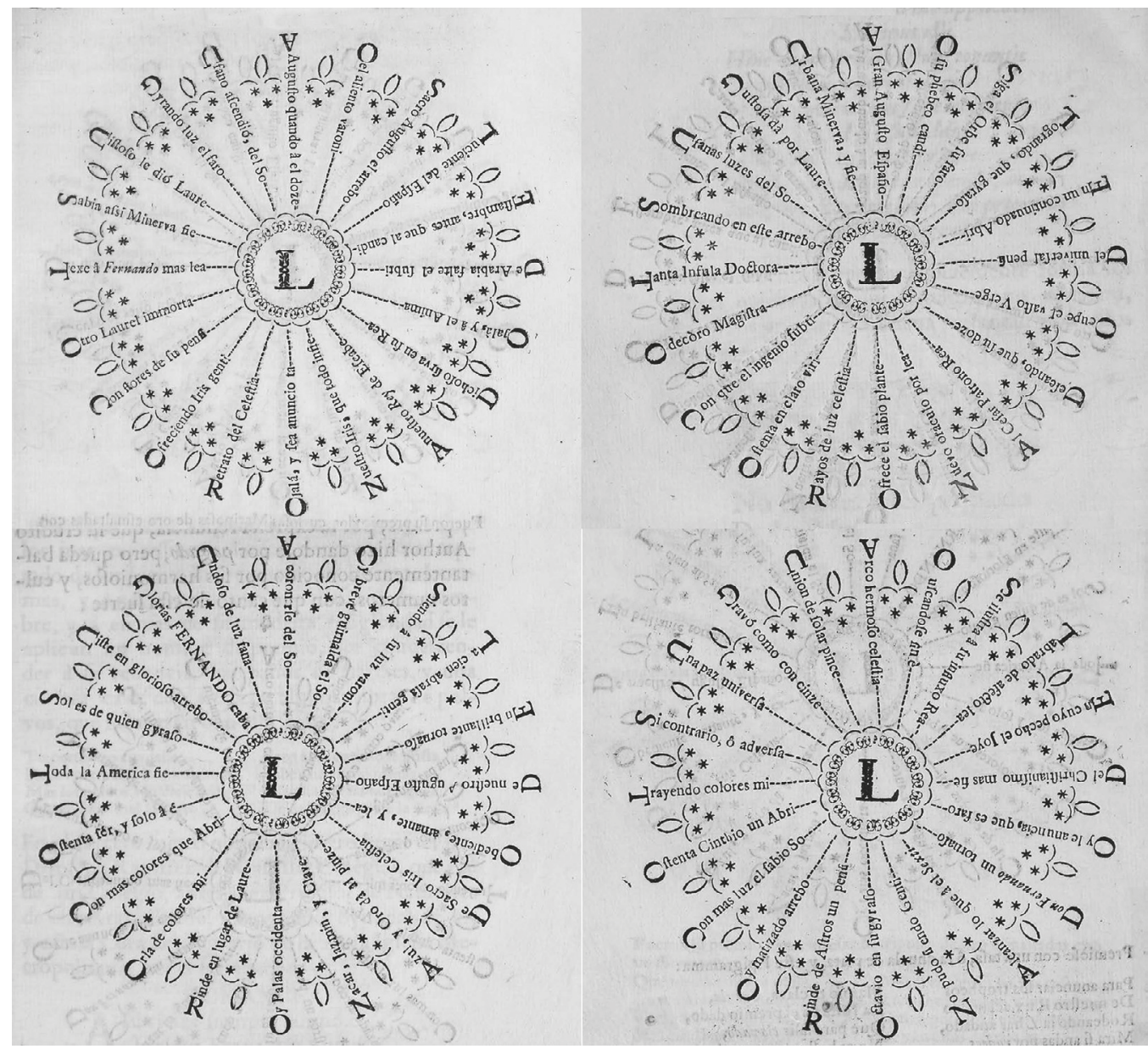

Fig. 1. Décimas acrósticas y forzadas (en Rodríguez de Arizpe 1748: 41-44).

Estos astros, debidos a la pluma de Vicente Ferrer Díaz (derecha arriba), Mariana Navarro (izquierda arriba), Manuel Cazela (derecha abajo) y a un anónimo (izquierda abajo), resultaron ganadores en una de las varias categorías de un certamen poético novohispano del siglo 


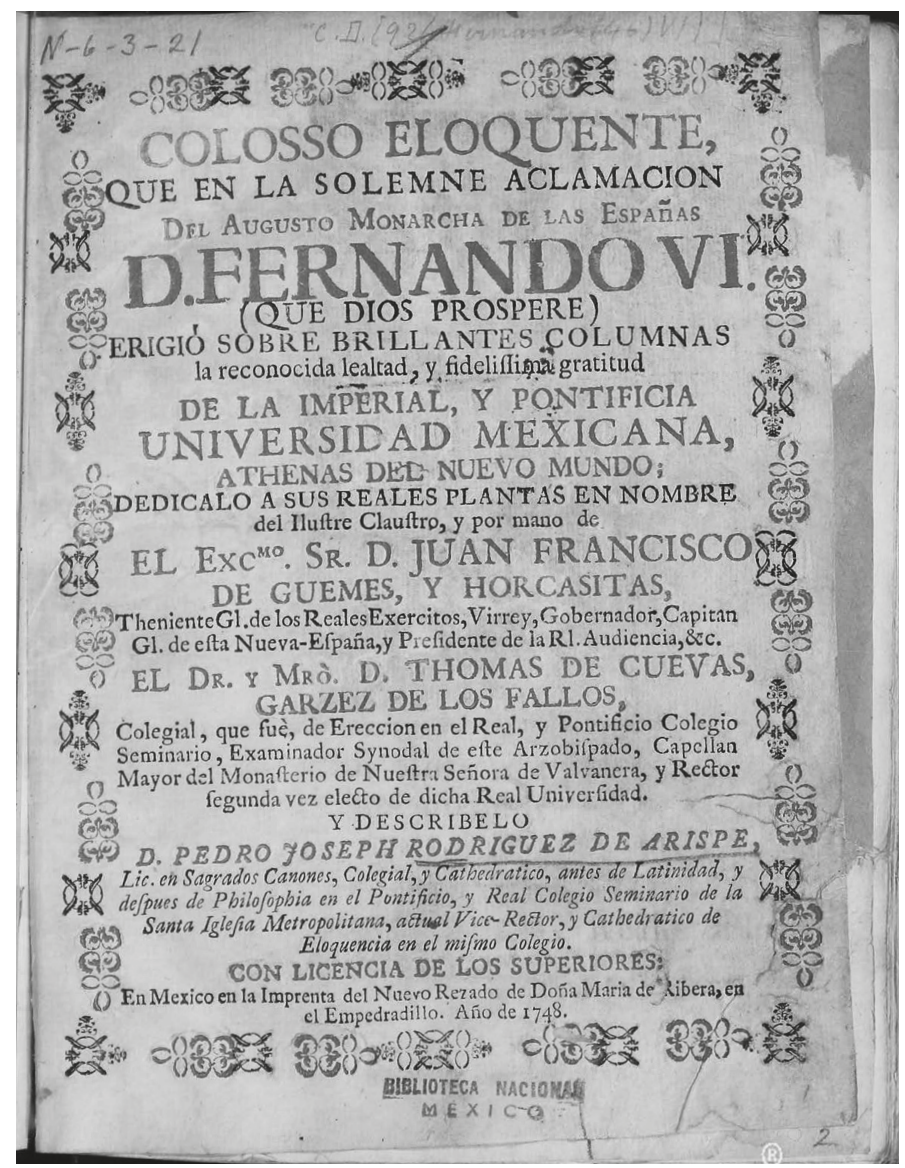

Fig. 2. Portada del Coloso elocuente (México: Nuevo Rezado de Doña María de Ribera, 1748).

XVIII. Este fue organizado por la Real y Pontificia Universidad de México en diciembre de 1747 para honrar a Fernando VI en su exaltación al trono. De los pormenores del certamen y de las celebraciones diversas que lo engalanaron da cuenta la relación o relato del mismo, escrita por Pedro José Rodríguez de Arizpe, la cual se publicó un año después bajo el título de Coloso elocuente. Hasta ahora, el texto íntegro no ha sido editado modernamente y del mismo solo se conoce la editio princeps; he consultado para la redacción de estas líneas el ejemplar resguardado en la Biblioteca Nacional de México (signatura RSM 1748 M4ROD) (fig. 2) ${ }^{1}$.

Gracias a los datos proporcionados por José Mariano Beristáin y Souza en su Biblioteca hispanoamericana septentrional y por los que aparecen en las portadas de algunas de sus obras impresas, podemos bosquejar la trayectoria vital del autor, nacido en México hacia 1715.

1 Algunos poemas del certamen han sido editados por Tenorio en su magistral Poesía novohispana. Antología; se trata de unas octavas que pueden leerse también como redondillas, debidas a la pluma de Ana María González y Zúñiga (2010: 1105-1106); además, unas "líricas" o sextetos-liras y una canción con los mismos consonantes de otra de Luis de Góngora, ambas composiciones de autoras anónimas (1115-1117). 
Su primera obra publicada parece ser el Alegórico simulacro del célebre príncipe Atlante, una descripción del arco triunfal que la Catedral Metropolitana erigió para recibir al virrey Juan Francisco Güemes y Horcasitas en 1746 (México: Viuda de José Bernardo de Hogal). Para entonces (contaba con 31 años) ya era licenciado en Derecho canónico, e impartía las cátedras de Latinidad, Retórica y Filosofía en el Real Colegio Seminario de la Catedral Metropolitana, del que era, además, vice-rector. Siguió siéndolo al menos hasta 1748, año en que se imprimió la obra que aquí nos ocupa. Para 1753, año en que se da a las prensas su Relación de lo acaecido en la celebración del jubileo (México: Nueva Imprenta de la Biblioteca Mexicana), ya se había doctorado en sagrados cánones y se había retirado al Oratorio de San Felipe Neri, del que fue, según Beristáin, prepósito. En 1771 fue consultor del IV Concilio Provincial Mexicano. Además de la relación del certamen que aquí nos ocupa y de las obras a las que nos hemos ya referido, publicó algunas otras obras de carácter pedagógico: una Explicación de las oraciones latinas, una Instrucción para hacer versos latinos, etcétera. Desconozco la fecha de su muerte. En suma, como dice Beristáin, "sirvió al público en la enseñanza de la juventud, en la predicación de la divina palabra y en la dirección espiritual de las almas con incansable aplicación y celo" (1816: s.v.: Arizpe). También, añadiría, supo divertirse y estar muy cerca de las altas esferas del poder: ideó el arco triunfal para recibir a un virrey y fue secretario de un exquisito certamen poético de la universidad.

He dicho que el rescate documental tiene algo de arqueológico. Tal como ocurre en una excavación, el contexto es fundamental: a veces un hallazgo nos deslumbra y dejamos de prestar atención a aquello que lo rodea. Eso nos impide entender la naturaleza y función del objeto encontrado. El Coloso elocuente es, como gran parte de la literatura novohispana, una obra con sus valores intrínsecos pero, al mismo tiempo, una obra que depende enteramente de sus circunstancias: hecha para un tiempo y momento específicos. Si desatendemos el contexto particular que motivó la creación de ciertas obras novohispanas, toda interpretación de su significado último será parcial o, en el peor de los casos, completamente desatinada. Para aproximarnos al resplandor de astros como los antes referidos sin deslumbrarnos, hay que indagar antes en el certamen poético en el cual fueron premiados y en la compleja celebración de la cual formaban parte: sus razones, sus objetivos, sus temas, el estilo del resto de los poemas participantes.

Este certamen y su relación, al igual que gran parte de nuestra literatura dieciochesca, ha sido ignorado por la crítica. Tal indiferencia es incomprensible e injustificada porque el concurso y el texto de Rodríguez de Arizpe están lejos de ser, como veremos, otros más del montón. La fiesta que vislumbramos a través del relato del Coloso constituye un capítulo importante de la vida cultural novohispana y las composiciones del certamen dan cuenta de ese periodo de las letras novohispanas que durante buena parte del siglo XVIII prolongó, intensificándola, la estética del Barroco, y que no podemos tildar sino de ultrabarroco. Para mostrar lealtad al monarca y a su esposa, Bárbara de Braganza, los académicos echaron la casa por la ventana: en la fiesta se derrocharon riquezas y en los poemas del certamen, ingenio. 


\section{Un coloso sobre columnas de fuego: los festejos en torno al certamen}

Es bien conocida la debilidad de los novohispanos por la fiesta: la llegada de un virrey, el cumpleaños de la reina, la consagración de un arzobispo o el día de un santo especialmente venerado echaban a andar un complejo engranaje festivo. Pero la pirotecnia se disuelve en la sombra, se acalla el fragor de los toros en el ruedo y la arquitectura frágil de arcos y túmulos se desmorona. Pervive solamente la relación, el relato, a través de la cual podemos vislumbrar el esplendor de la fiesta. Esas relaciones, que se imprimieron por montones y constituyen un verdadero subgénero de la literatura novohispana, no se limitan, claro está, a narrar objetivamente la celebración: si esta había sido esplendorosa, el relato de la misma debía equiparársele. Hechas de suntuosos endecasílabos, dioses, ninfas e imaginería gongorina, las relaciones inventan otra fiesta que, gracias al milagro del arte, ha sido aprisionada tras las líneas en el papel: la poesía, como diría Octavio Paz (1972: 185 y ss.), ha consagrado el instante y lo ha extraído del avance sin tregua de los siglos. La fiesta es efímera; la letra permanece.

Ahora bien, si el goce de la fiesta estaba al alcance de todos, el código para escribir y desentrañar la relación escrita lo poseía únicamente la élite letrada que, a través del texto, perseguía intereses que iban más allá del momentáneo regocijo. La relación se imprimía para dejar constancia de los acontecimientos y, sobre todo, de quiénes los habían hecho posibles. En estos impresos cada participante aparece por nombre y apellidos: había que dejar muy claro al virrey, al rey o a quien conviniera qué personajes habían demostrado su lealtad mediante el patrocinio y realización de la fiesta. Estos personajes buscaban con ello, por supuesto, obtener algún cargo, algún favor. La élite podía, además, por medio de los textos "difundir dogmas y convicciones oficiales" (Pascual 1959: 21) y, al mismo tiempo, "exaltar —mediante demostraciones de diversos valores y creencias: amistad, lealtad, admiración, respeto, etcétera- a una entidad tangible - una persona- o abstracta - la patria, Dios...” (Rodríguez Hernández 2014: 134). Las relaciones impresas que dan cuenta de celebraciones relacionadas con el monarca tienen como objetivo central mostrar la absoluta lealtad y adhesión del reino novohispano a la Corona. En el caso del Coloso elocuente, el panegírico al rey por parte de los académicos tenía, además de ese objetivo, el de velar por el patronato real, es decir, por el financiamiento del rey español que sostenía la Real y Pontificia Universidad².

Entre las relaciones de fiestas novohispanas, las que se ocupan de los certámenes literarios merecen una mención aparte. Un certamen poético novohispano tiene poquísima semejanza con nuestros certámenes actuales. En primer lugar, un poeta que concursara en una lid de la época no tenía, como hoy, la prebenda de la forma y el tema libre; todo el concurso estaba regido por una suerte de supra concepto: se entablaba una relación entre el personaje homenajeado y, por ejemplo, otro de la antigüedad grecolatina. En el caso del certamen del que da cuenta el Coloso se entablaba una semejanza entre Fernando VI, el emperador romano Octavio Augusto y el sol. Una vez establecida la idea general, se delineaban varios asuntos o sub-certámenes que constituían las diferentes categorías del concurso. Cada una otorgaba, por lo general, tres

2 Habría que puntualizar intereses más concretos de los universitarios en este período, ahondar en el estado de las relaciones entre la autonomía de la universidad y el rey anterior, Felipe V, y determinar si existía descontento a causa de reformas emprendidas por la dinastía borbónica que afectaran a la academia mexicana en esta primera mitad de siglo. 
primeros lugares y tenía un tema, un tratamiento y exigencias métricas específicas a las que se debían ceñir los participantes. Por ejemplo, en el certamen tercero del Coloso elocuente se recalcó la afición que Augusto sentía por la paz y la esperanza de que, como imagen suya, el rey español extinguiera los "fatales asedios de la guerra" y trajera consigo "de la apetecida paz las prosperidades" (Rodríguez de Arizpe 1748: 67). Lo anterior debía verterse en un soneto cuyos versos remataran todos, sin excepción, en una palabra esdrújula.

En segundo lugar, hay que dejar en claro que un certamen no implicaba únicamente la recepción y premiación pública de los poemas vencedores. La lid literaria constituía el núcleo de una serie de regocijos que podían incluir cabalgatas, convites lujosos o conciertos. Por lo general, las relaciones de certámenes, amén de los preliminares de rigor, constan de dos grandes secciones: una dedicada a la pormenorizada relación de estas fiestas, casi siempre escrita por el secretario del certamen — suerte de presidente del jurado y responsable de la idea general de la fiesta-; otra, a la publicación de los poemas ganadores ${ }^{3}$.

Ese es justamente el caso del Coloso elocuente, cuyo volumen está conformado por dos grandes bloques. En el primero, Rodríguez de Arizpe recrea las fiestas que precedieron a la pública premiación de los poemas del certamen o, como él dice, a la "erección del elocuente coloso del coronado Augusto de las Españas”. Esto último está relacionado con la idea que da nombre al volumen y que valdría la pena explicar. Existe la noticia, que se remonta a Plinio (lib. XXXVI, cap. 7) ${ }^{4}$, de que uno de los colosos de Memnón, estatuas de Amenoteph III que se creían construidos dentro del templo de Serapis, murmuraba cada mañana en cuanto lo doraban los rayos del sol: "Venerábase colocada en este suntuoso edificio [...] aquel celebérrimo milagro de los siglos, el coloso o estatua de Memnón, harmoniosa cítara de mármol que, luego que la tocaban los rayos del sol, se manifestaba elocuente en acentos sonoros" (Rodríguez de Arizpe 1748: LXXXVI). Dado que el templo egipcio por su "simetría espaciosa", según Rodríguez de Arizpe, fue una "sombra, aunque lucida", es decir, un bosquejo del original que sería el edificio de la universidad, los académicos erigirían dentro de este otro coloso, no de piedra, sino de poemas, que, "tocado de los métricos rayos de Apolo", hablaría en "numerosos acentos" (1748: LXXXVII). Ese Apolo, el sol, es, por supuesto, Augusto y, al mismo tiempo, Fernando VI. ${ }^{5}$

Apenas el virrey le notificó la exaltación al trono de Fernando VI, el rector decidió que un certamen universitario sería la mejor manera de celebrar. La fiesta relatada en el Coloso elocuente, como la de prácticamente todos los certámenes novohispanos, dio principio con el paseo de la tarja (o cartel) el 26 de noviembre de 1747. Las exigencias del certamen y de

3 A propósito de los certámenes literarios novohispanos véanse los textos pioneros de Reyes (1946/2007: 97-100) y Leonard (1974: 191-228); y el antes citado de Pascual (1959).

4 El texto latino dice: "illi narratur in Thebis delubro Serapis, ut putant, Memnonis statuae dicatus, quem cotidiano solis ortu contactum radiis crepare tradunt”; en la traducción de Jerónimo de la Huerta, realizada en el siglo XVII, se lee: "Semejante a este [el mármol conocido como basalte] se cuenta ser el que, como algunos piensan, se dedicó con la estatua de Memnón en Tebas en el templo de Serapis, el cual, tocado cada día con los rayos del sol cuando sale, dicen que hace estruendo".

5 Una comparación entre este tipo de festividades en Nueva España y otras semejantes en el Viejo Continente está fuera de los límites de este trabajo. Hay que destacar, con todo, que las festividades oficiales en la Península dedicadas a los monarcas se realizan de modo muy similar y se valen del mismo imaginario, alegorías, retórica, etcétera. Esta identificación de Apolo con el rey, por ejemplo, era frecuentísima en ambos lados del Atlántico (véase Hernández 2014: 115-118). 
cada uno de sus asuntos se detallaban en esa tarja que recorría las principales calles de la ciudad en una procesión conformada por los colegios académicos, montados en caballos y mulas ricamente enjaezados que, entre la música de clarines y atabales, "formaban una moble vistosa primavera de costosas galas" (Rodríguez de Arizpe 1748: X). La gente salía a los balcones, a las puertas, a las calles, a ver pasar aquella comitiva que "daba alas para presumirse bello pavón de damasco y oro" (1748: XII). Luego de su paseo, el cortejo que anunció el certamen descrito en el Coloso elocuente - que como el pavorreal de Tablada, "largo fulgor", "por el gallinero demócrata” pasó “como una procesión”- volvió a la universidad de donde había partido. Fijó el cartel en la puerta interior del pórtico y, con él, la fecha límite para entregar los poemas: 14 de diciembre.

Mientras los poetas tomaban nota de las exigencias, se mordían las uñas, se partían la cabeza frente a las hojas en blanco y, luego de varios desvelos, enviaban sus poemas por duplicado (una copia anónima y otra con nombre en sobre cerrado), la universidad aprovechó para celebrar el cumpleaños de la reina, María Magdalena Bárbara de Braganza. Cuando hablamos del fasto en la fiesta novohispana no hace falta ninguna hipérbole. El 4 de diciembre, día del cumpleaños de la reina, la universidad decidió erigir en el espacio que hoy ocupa el Zócalo de la Ciudad de México cinco columnas de fuego que servirían de basa al elocuente coloso, hecho de versos, que se avecinaba:

Fueron lucido desempeño de los académicos deseos cinco artificiosas invenciones, cuya primorosa perspectiva hizo perceptible la industria, disipando el funesto embarazo de las tinieblas con veinte y cuatro barriles de fuego (exquisita especie de luminarias que ha inventado nuevamente esta lucidísima arte) que, distribuidos a proporcionadas distancias e iluminados por ocultos conductos, se convirtieron en claras y elevadas llamas que ilustraron sobradamente todo el espacio de la Plaza Mayor (Rodríguez de Arizpe 1748: XIX).

El solo hecho de ver cinco columnas de fuego iluminar la plaza entera debía ser ya un gran espectáculo pero la fiesta novohispana siempre deleitaba, además de a los sentidos, al intelecto. Cada una de estas llamaradas se acompañaba de una pieza efímera y eruditísima de 20 metros de altura aproximadamente. Esa noche los novohispanos vieron, a la luz de las altivas llamas, un castillo seisavado con un águila bifronte en la cumbre, una pirámide de seis cuerpos coronada del sol, un florido pensil ${ }^{6}$ que incluía un águila real sobre las nopaleras, un árbol en cuyas ramas se posaban otras águilas y otro sol y, por último, una flor abierta como una corona imperial ${ }^{7}$. Cada una de estas figuras tenía, además de mecanismos que posibilitaban el movimiento de sus partes, un lema y un breve poema a modo de epigrama: estamos ante un caso excepcional de emblemas corporeizados y vivientes.

6 pensil: en rigor, es solamente el "jardín que está como suspendo o colgado en el aire", pero puede referir a "cualquier jardín delicioso" (Diccionario de Autoridades.).

$7 \quad$ Nótese la importancia del número seis (el esposo de la reina consorte era el sexto Fernando) en las piezas; además de inspirar estas últimas, el seis fue el sostén alegórico-simbólico de otro certamen celebrado por el Colegio de San Ildefonso de México en enero de 1748, poco después de este que nos ocupa: la Cifra feliz de las dichas imponderables que se promete la monarquía española bajo el dominio de su augusto soberano el señor don Fernando VI (Salamanca: Imprenta de la Santa Cruz, s.a.). Puede verse un poema visual de este certamen, una figura compuesta por seis círculos alrededor de uno central en los que se inscriben otras tantas estrofas, en honor a Bárbara de Braganza en Gutiérrez (2014). 
A pesar de que estas piezas estaban dedicadas a celebrar el cumpleaños de Bárbara de Braganza, Fernando VI tiene en ellas un papel protagónico. Me detengo brevemente en una de estas con el fin de evidenciar la espectacularidad de su factura y la complejidad del discurso que proponían al auditorio. La segunda de las piezas estaba constituida por una pirámide de seis cuerpos de 17 metros de altitud, coronada de un sol, "entre cuyos rayos se percibía un escudo en que a todo primor se esculpió la venerada imagen del católico Augusto. Servíanle de vistoso adorno diez y seis palmas, doce abanicos y otras tantas piezas de guerra" (Rodríguez de Arizpe 1748: XXII y ss.).

Si Fernando era imagen de Augusto, Bárbara lo era también de su esposa Livia, cuya prenda más vistosa solía ser la prudencia. La pirámide de la pieza — con base en el Mundus symbolicus de Picinelli (lib. XVI, cap. 16, n. 153) - simbolizaba la prudencia de la que también hacía gala la reina consorte, bañada, al igual que su marido, por los rayos del sol; estos últimos junto con la pirámide convenían al nombre de Bárbara pues, según Rodríguez de Arizpe, que cita de nuevo a Picinelli (lib. XVI, cap. 16, n. 171), “bárbaras” llamó a las pirámides de Menfis Karl Ludwig en su Philothei symbola christiana. Los abanicos de la pieza simbolizaban "el buen viento que sus leales dominios desean le corra en las continuadas guerras", representadas estas por las armas bélicas presentes en la pieza. Las palmas vendrían a augurar los triunfos en las batallas que libraría el monarca. Todo este complejo discurso se hallaba sintetizado en el lema "Barbara sic prudens consumit pyramis umbras" ('Bárbara así prudente disipa, pirámide, las sombras') y en la siguiente décima:

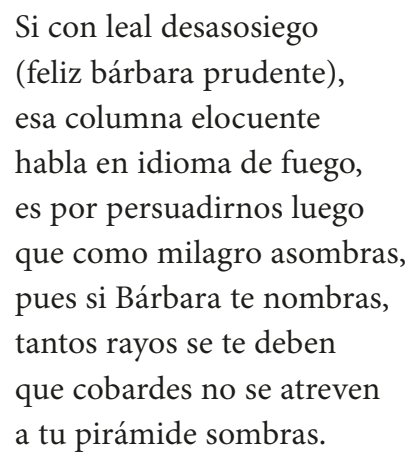

En la víspera de la premiación, la cual se llevaría a cabo el 20 de diciembre, la universidad encendió numerosas antorchas en los balcones y azoteas de su edificio. Hubo luego castillos y toros de pirotecnia que deleitaron a los ciudadanos. Esas luces, como dice Arizpe - entre cuyas líneas a veces asoma Góngora y otras, sor Juana- "formaron un capaz sol para iluminar sobradamente todo aquel dilatado espacio, haciendo que cobarde retirase sus silenciosas sombras la noche" (1748: XLII).

Hasta entonces el festín había ofrecido únicamente sus aperitivos: "Llegó en fin el deseado día veinte de diciembre, a cuyo centro tiraban las líneas de las referidas prevenciones para sacar a luz los merecidos triunfos de los vencedores adalides" (Rodríguez de Arizpe 1748: XCIII). Esa noche de invierno la universidad recibió 600 invitados, todos ansiosos de conocer a los ganadores del certamen y de deleitar sus oídos con los poemas y la música que de cuando en 
cuando interrumpía deleitosamente la ceremonia. Pero, además de los oídos, la vista también se recreaba. Los académicos buscaron "imitar a esmeros del arte a aquella decantada fuente del Parnaso, Aganipe, cuyas cristalinas ondas (para ser ameno domicilio de las musas y diáfano espejo de Apolo tan estimado, que se está mirando en él) fecundan sus riveras con vistosa multitud de flores" (Rodríguez de Arizpe 1748: LXXIX). ¿Cómo lograron que la Real Universidad se asemejara a este sitio tan ameno? Desde el pórtico hasta el aula mayor se cubrió cada centímetro del techo y los muros con vistosas y floridas colgaduras turquescas de damasco encarnado y de seda, sobre las cuales se dispusieron más de 100 espejos y pantallas de oro y plata que multiplicaban la luz de numerosos candiles. Los decorados también, como señala Hernández a propósito de celebraciones semejantes en España, ocultaban "la inmovilidad de los edificios" y los transformaban "en nuevos espacios abiertos" (2014: 104-105). Dentro de la universidad, el día no sucumbió a los embistes de la noche:

Se le fue a la vista por alto la materia del techo, por haberla ocultado de su curioso registro las bellas cortinas, que lo convirtieron en cielo, cuyos luminares fueron hermosos candiles de plata que con lucidas antorchas privaban aquel espacio de la opaca posesión de las tinieblas; pues, aun acabado el día, parecía que no comenzaba la noche (Rodríguez de Arizpe 1748: LVII).

Entre espejo y espejo, numerosos retratos de los reyes y emblemas reiteraban la alegoría del certamen: por aquí se veía al rey vestido de Augusto y coronado del sol, más allá, se le veía como Apolo, inventor de la medicina, repartiendo remedios a los hombres. En el aula mayor, donde se llevaría a cabo la premiación del certamen, había una mesa cubierta de terciopelo sobre la que relumbraban las alhajas que esa noche se otorgarían a los vencedores.

En el Barroco, vivo e intensificado durante el siglo XVIII novohispano, el artificio vence a la naturaleza: "Es el arte complemento de la naturaleza y un otro segundo ser que por extremo la hermosea y aun pretende excederla en sus obras. Préciase de haber añadido un otro mundo artificial al primero: suple de ordinario los descuidos de la naturaleza, perficionándola en todo" (Gracián 1669: 64). Es notorio que Rodríguez de Arizpe busca dejar constancia en su Coloso elocuente de que en aquella fiesta el arte no solo imitaba a la idílica naturaleza, sino que la vencía.

\section{El ultrabarroco: gran vencedor del Coloso elocuente}

Puedo decir, sin exagerar, que el segundo de los bloques que lo erigen, el dedicado a dar cuenta de las composiciones premiadas, convierte al Coloso elocuente en uno de los libros más experimentales de la poesía mexicana. La literatura novohispana no puede analizarse desde una perspectiva eurocéntrica: sigue su propio camino y este muchas veces difiere del de la literatura peninsular. En el caso particular de la poesía, durante el siglo XVIII novohispano no se recibió al neoclásico ni con particular entusiasmo ni del mismo modo que en otras latitudes. Muchas de las tendencias del Barroco, como ya dije, se continuaron e, incluso, se intensificaron durante esta centuria: los poetas convirtieron su quehacer poético, en palabras de Alfonso Reyes, en "un pequeño y activo laboratorio, verdadera estación experimental” (1946/2007: 98). Llevaron, pues, el extremo al extremo. 
La audacia del artificio en los poemas que componen el que podríamos llamar un certamen clásico novohispano — por ejemplo, el Triunfo parténico (México: Juan de Ribera, 1683) - no puede compararse con la que se luce en las obras del Coloso elocuente, celebrado más de 60 años después. A este último, una pista de numerosas y riesgosas acrobacias poéticas, me gusta tildarlo de ultrabarroco. El lector se topará, quizá más que en ningún otro certamen, con laberintos, acrósticos, poemas ecoicos, retrógrados, centones, paramofrones, etcétera.

Ahora bien, el barroquismo del Coloso tiene sus asegunes. No cabe duda de que la lengua predilecta de la lírica oficial novohispana, la poesía de los certámenes, fue la gongorina, sobre todo aquella que se despliega en el Polifemo o las Soledades, y que, de hecho, gongorismo y Barroco se emplean muchas veces como sinónimos. Quien se haya adentrado en la lectura de estos poemas sabrá que las dificultades a vencer para llegar a comprenderlos plenamente son diversas y van más allá del terreno estrictamente formal: el hipérbaton, las palabras utilizadas en un sentido etimológico, las metáforas no siempre fáciles, el dominio del concepto.

Hay que decir que esa complejidad conceptual en el Coloso escasea: el intrincado concepto, la imagen dificultosa han cedido completamente al imperio de la forma. Los contenidos de los textos de este certamen, salvo raras excepciones, no son demasiado elaborados, y basta conocer bien a bien las fuentes y el contexto para entenderlos a cabalidad. Los poetas apostaron por el artificio en lo externo, por la espectacularidad de la apariencia: hubiera sido mucho pedir que un poema que puede leerse de 8 o más maneras distintas emprenda, además, sublimes vuelos metafóricos. Tenorio afirma que los certámenes en el siglo XVIII “empezaron a perder sus «gongóricos» acentos" (2013: 205); es cierto: pero, al menos en el caso del Coloso, esa pérdida no implica necesariamente, como veremos, un distanciamiento de la estética barroca. Hay, pues, una transparencia (neoclásica, si se quiere) en los contenidos y un ultrabarroquismo en los mecanismos formales que echan a andar estos poemas.

60 poemas en total resultaron ganadores en el Coloso elocuente. Sin duda, el más aventurado de estos se debe a la pluma de Francisco Díaz. Beristáin (1816: s.v. Díaz Olivares) consigna en su Biblioteca hispanoamericana septentrional a un Francisco Díaz Olivares. Según el bibliógrafo, este nació en Veracruz, fue estudiante y después catedrático del Seminario Palafoxiano de Puebla. Se doctoró en la Ciudad de México y se desempeñó como calificador del Santo Oficio de la Inquisición; también ocupó algunos cargos eclesiásticos tanto en Cholula como en Puebla. En esta ciudad le fue encargado el arco triunfal para recibir al duque de Albuquerque, que tomó posesión del virreinato de la Nueva España en 1702, y publicó algunas obras entre 1694 y 1721. Tenorio (2010: 947) habla asimismo de un Francisco Díaz que formaba parte de la Academia Guadalupana, suerte de tertulia en la que algunas personas se reunían para componer versos. Tal academia sesionó en México alrededor de 1720, bajo la presidencia de fray Juan Antonio de Segura Troncoso, calificador de la Inquisición. Recordemos que el Díaz Olivares registrado por Beristáin trabajó asimismo para el Santo Oficio, donde pudo entrar en contacto con Segura y Troncoso; así pues, es posible que el Díaz a secas del que habla Tenorio sea el mismo que aparece en la Biblioteca hispanoamericana. Quizá se trate del autor aquí presentado, que ya en 1747, fecha del Coloso elocuente, sería un hombre maduro.

Díaz presentó su poema en una categoría que pedía celebrar la capacidad del monarca para mantener la paz a partir de una astuta legislación. Consiguió un irrebatible primer lugar: según consta en el impreso original, el autor había enviado sus cuartillas creyendo que solamente 
podían leerse de ocho modos distintos, pero "hizo más de lo que pensó", pues "la curiosidad de la justa, escudriñando los ocho, descubrió dieciséis: los ocho de arriba para abajo, y los otros ocho de abajo para arriba" (Rodríguez de Arizpe 1748: 86). Estamos ante un poema retrógrado llevado al extremo ultrabarroco: lo normal es que se escribieran poemas que pudieran leerse de abajo para arriba y viceversa, nada más. Reproducimos las 16 maneras distintas, detalladas en el Coloso elocuente, en que pueden leerse las quintillas, utilizando como ejemplo la primera de ellas:

El primero modo de arriba a abajo es el regular de esta manera:
A España-domina-augusto
Celoso-el sexto-Fernando,
Sin saña, — sin mal, —sin susto,
juicioso-en su era'
la cizaña-de-lo injusto.

El segundo es retrocediendo de esta suerte:

$$
\begin{aligned}
& \text { Augusto-domina-a España } \\
& \text { Fernando-el sexto-celoso, } \\
& \text { sin susto, - sin mal, —sin saña, } \\
& \text { segando-en su era-juicioso } \\
& \text { lo injusto-de-la cizaña. }
\end{aligned}
$$

El tercero es leyendo el primero pie para adelante y el segundo para atrás, etcétera, así:

$$
\begin{aligned}
& \text { A España-domina-augusto } \\
& \text { Fernando-el sexto-celoso, } \\
& \text { sin saña, - sin mal, - sin susto, } \\
& \text { segando-en su era-juicioso } \\
& \text { la cizaña-de-lo injusto. }
\end{aligned}
$$

El cuarto es, leyendo al contrario el primer pie para atrás y el segundo para adelante, etcétera, de esta suerte:

$$
\begin{aligned}
& \text { Augusto-domina-a España } \\
& \text { celoso-el sexto-Fernando, } \\
& \text { sin susto, - sin mal, —sin saña, } \\
& \text { juicioso-en su era-segando } \\
& \text { lo injusto-de-la cizaña. }
\end{aligned}
$$

8 El resto de las quintillas que componen el poema pueden leerse en Gutiérrez (2014).

9 Era: "pedazo de tierra limpia y bien hollada en que se trillan las mieses" (Diccionario de Autoridades). 
El quinto es comenzando a leer por el tercero pie para abajo y después los dos de arriba, de esta manera:

$$
\begin{aligned}
& \text { Sin saña, — sin mal, —sin susto, } \\
& \text { juicioso-en su era-segando } \\
& \text { la cizaña-de-lo injusto, } \\
& \text { celoso-el sexto-Fernando } \\
& \text { a España-domina-Augusto. }
\end{aligned}
$$

El sexto es retrocediendo en la misma lectura del tercero pie, etcétera y así:

$$
\begin{aligned}
& \text { Sin susto, - sin mal, —sin saña, } \\
& \text { segando-en su era-juicioso } \\
& \text { lo injusto-de-la cizaña, } \\
& \text { Fernando-el sexto-celoso } \\
& \text { a España-domina-augusto. }
\end{aligned}
$$

El séptimo es leyendo desde el tercero, un pie para adelante y otro para atrás de esta manera:

$$
\begin{aligned}
& \text { Sin saña, - sin mal, - sin susto, } \\
& \text { segando-en su era-juicioso } \\
& \text { la cizaña-de-lo injusto, } \\
& \text { Fernando-el sexto-celoso } \\
& \text { a España-domina-augusto. }
\end{aligned}
$$

El octavo es leyendo al contrario un pie para atrás y otro para adelante comenzando también por el tercero, de esta suerte:

$$
\begin{aligned}
& \text { Sin susto, — sin mal, —sin saña, } \\
& \text { juicioso-en su era-segando } \\
& \text { lo injusto-de-la cizaña, } \\
& \text { celoso-el sexto-Fernando } \\
& \text { augusto-domina-a España. }
\end{aligned}
$$

Los otros ocho modos se hayan leyendo de abajo para arriba, en que se verifica lo retrógrado, verbigratia:

$$
\begin{aligned}
& \text { La cizaña-de-lo injusto } \\
& \text { juicioso-en su era-segando } \\
& \text { sin saña, - sin mal, - sin susto, } \\
& \text { celoso-el sexto-Fernando } \\
& \text { a España-domina-augusto. }
\end{aligned}
$$


O retrocediendo así:

Lo injusto-de-la cizaña

segando-en su era-juicioso

sin susto, — sin mal, —sin saña,

Fernando-el sexto-celoso

Augusto-domina-a España.

Leyendo un pie para adelante y otro para atrás:

La cizaña-de-lo injusto

segando-en su era-juicioso

sin saña, — sin mal, —sin susto,

Fernando-el sexto-celoso

A España-domina-augusto.

Al contrario:

Lo injusto-de-la cizaña

juicioso-en su era-segando

sin susto, — $\sin$ mal, — sin saña,

celoso-el sexto-Fernando

Augusto-domina-a España.

Comenzando por el tercero pie para arriba, etcétera:

Sin saña, - sin mal, — sin susto,

celoso-el sexto-Fernando

a España-domina-augusto,

juicioso-en su era-segando

la cizaña-de-lo injusto.

Comenzando por el mismo pie para atrás:

Sin susto, — sin mal, —sin saña,

Fernando-el sexto-celoso

augusto-domina-a España,

segando-en su era-juicioso

lo injusto-de-la cizaña. 
Leyendo un pie para adelante, y otro para atrás comenzando por el tercero:

$$
\begin{aligned}
& \text { Sin saña, - sin mal, — sin susto, } \\
& \text { Fernando-el sexto-celoso } \\
& \text { a España-domina-augusto, } \\
& \text { segando-en su era-juicioso } \\
& \text { la cizaña-de-lo injusto. }
\end{aligned}
$$

\section{Al contrario:}

$$
\begin{aligned}
& \text { Sin susto, — sin mal, —sin saña, } \\
& \text { celoso-el sexto-Fernando } \\
& \text { augusto-domina-a España, } \\
& \text { juicioso-en su era-segando } \\
& \text { lo injusto-de-la cizaña. }
\end{aligned}
$$

Por este poema, una de las empresas más descabelladas del ingenio virreinal, Francisco Díaz se llevó "un cintillo de oro con una esmeralda y dos diamantes"; también, como era costumbre en este tipo de actos, el presidente del jurado le ofreció las siguientes redondillas burlescas:
Cuando en retrógrado metro
tu consonancia se emplea,
a cualquiera que lo lea
dile luego vade retro.
Lleva el premio con que medras,
mas no con cordura poca
juzgues a la justa loca
solo porque arroja piedras ${ }^{10}$.
(Rodríguez de Arizpe 1748: 92).

El certamen sexto partía de la idea de que Fernando VI ostentaba el "debido título de poderoso rey y señor con que, leal y festiva, lo ha aclamado su fidelísima monarquía”. Al mismo tiempo, por la "humanidad y clemencia" con la que ha protegido a su reino, le conviene el "amable, divino nombre de padre". Los poetas debían "controvertir en métrica contienda cuál de estos títulos deba estimarse por más glorioso a su majestad augusta [...]: el de padre o el de rey" (Rodríguez de Arizpe 1748: 136). Francisco Xavier de la Zerda Morán, de quien no tengo noticia alguna, defendió en un soneto acróstico y forzado que al monarca español le venían los dos títulos sin que estos se contrapusieran entre sí (en Rodríguez de Arizpe 1748: 146):

10 Este último verso se refiere a las piedras preciosas que conforman el premio de Díaz y que el jurado le "arroja"; el chiste radica en la creencia de la época de que de los locos tiraban piedras por la calle: "hay dos grandes géneros de locos: unos que son locos de cabeza y ésos ni pecan ni merecen; tiran piedras por las calles y para tales se hicieron la casa de los orates en Valladolid y la Casa del Nuncio en Toledo. Otros hay locos de ingenio y estos son de grandísimo pecho para cuantas cosas hay en el mundo y cuando dan en santos son grandísimos santos" (Acevedo 1600: 327). La idea está también en el romance atribuido a Góngora, “Trepan los gitanos”: "Y si unos dan brincos / de rubíes y perlas, / otros como locos / tiran estas piedras” (1985: 296). 
Favor de rey, de padre afecto amable

En Fernando se ve cuando, apacible,

Rige su reino celo inextinguible,

Nudo haciendo a uno y otro inseparable.

A tanta majestad por respetable

Negar nombre de rey es imposible;

De su amor ocultar lo indefinible

Ofendiera de padre lo estimable.

Viva, pues su memoria y la voluble

Inconstancia del tiempo jure inmoble ${ }^{11}$

Reservarla de olvido que la nuble,

Eternizando así favor tan noble

Y erigiendo a esta unión indisoluble

Infinito PADRón, recuerdo doble ${ }^{12}$.

El soneto, salvo algunos bellos giros como "la voluble / insconstancia del tiempo", resulta bastante flojo y hasta prosaico. Lo interesante es el mecanismo formal: el acróstico se forma con cada una de las primeras letras de verso, con tres de las que conforman el último y con la última letra de cada uno: "Fernando VI, rey y padre". Vale la pena ver la forma en la que esta pieza se dispuso tipográficamente en el Coloso (véase Fig. 3 abajo).

Dado que el poeta se había hecho merecedor a una caja de plata en una categoría anterior del concurso, el jurado decidió no darle otro premio por este soneto.

Luego de este largo recorrido por el relato de la celebración y algunos de los poemas que triunfaron en la contienda poética, podemos volver a los cuatro astros que lo suscitaron. Estamos, como dijimos, ante unas décimas acrósticas y forzadas: el hecho de que, en su conjunto, las letras iniciales de cada verso formen la frase "Augusto coronado de so" y de que todos los versos terminen en la letra L, permite disponer el poema tipográficamente a modo de soles, de coronas (Fig. 1). Esta profunda unión entre forma y fondo los lleva, definitivamente, al terreno del caligrama: el poeta habla del sol y, al mismo tiempo, vemos sus rayos iluminando el papel $^{13}$.

No he sido el único al que estas composiciones poético-visuales han llamado poderosamente la atención. A pesar de que el Coloso elocuente no conoce una edición íntegra moderna, volvió a imprimirse solamente la décima acróstica escrita por Mariana Navarro. Hasta donde tengo noticia, el primero en darla a conocer, en siglo XIX, fue José María Vigil, que la incluyó en su antología Poetisas mexicanas (1893: 95). De esta antología la toma directamente José Vicente

\section{Inmoble: 'inmóvil'.}

12 Padrón: "columna de piedra con una lápida o inscripción de alguna cosa que conviene sea perpetua y pública" (Diccionario de Autoridades).

13 Existe en las letras novohispanas al menos otro poema acróstico con centro en la letra A y dispuesto visualmente a modo de sol; se trata de un soneto escrito por Francisco de Solís y Alcázar, publicado en la Descripción verdadera del general paraíso (México: Herederos de la Viuda de Francisco Rodríguez Lupercio, 1702), una obra sobre el Convento de San Juan Evangelista, dedicada a Diego Velázquez de la Cadena. Puede verse en Tenorio (2010: 875) y en Gutiérrez (2014). 


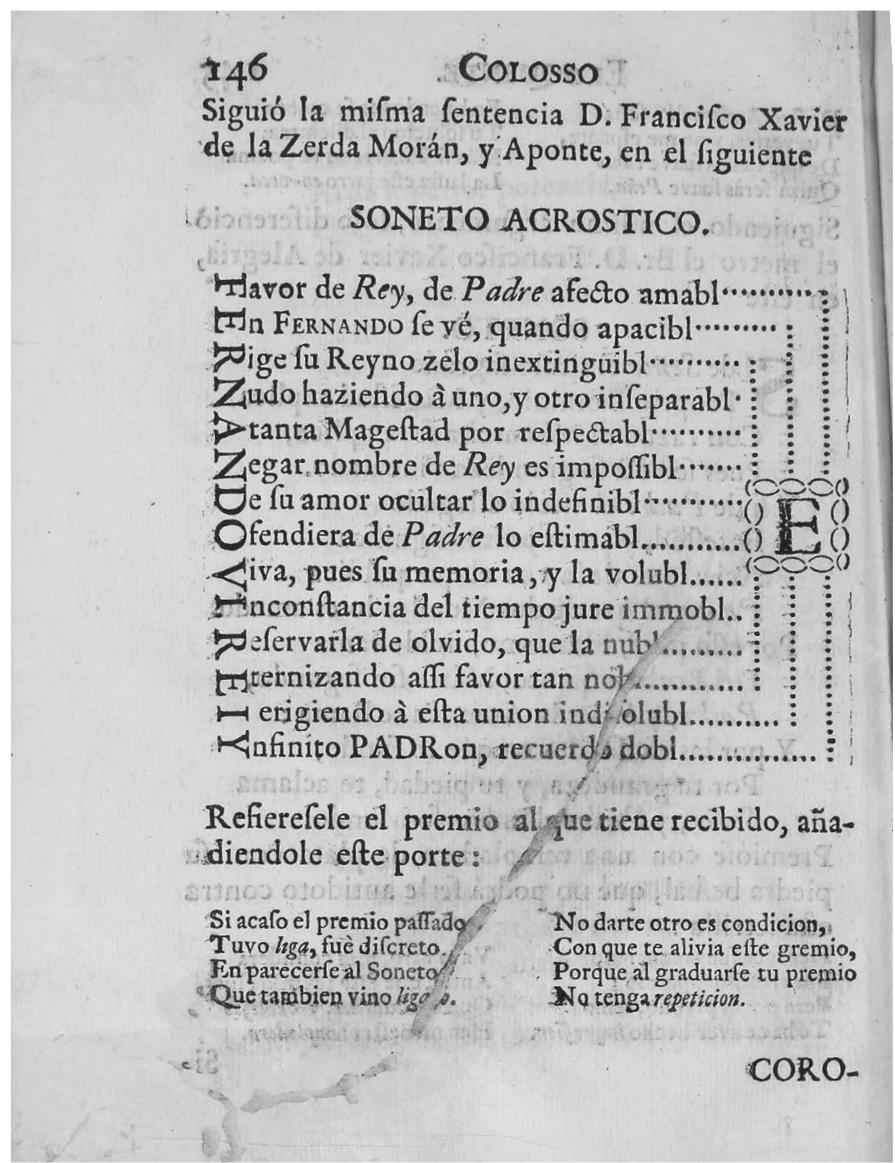

Fig. 3. Soneto acróstico y forzado de Francisco Xavier de la Cerda y Morán .

Anaya y la imprime en la revista Alforja (invierno 2002-2003: 10). Recientemente, la he sumado a mi antología Óyeme con los ojos. Poesía visual novohispana (2014), donde también edité las décimas de Vicente Ferrer Díaz que obtuvieron el primer lugar de la categoría.

Los poemas se pidieron a propósito de la anécdota siguiente: cuando Augusto tomó posesión del imperio romano, apareció una especie de círculo con los colores del arcoiris alrededor del sol. Este prodigio se formó "en modo de arco contiguo al solar orbe, mas en tal proporción que, correspondiendo a la regia cabeza de Augusto, parecía que el mismo sol se inclinaba a formar a tanto héroe la corona" (Rodríguez de Arizpe 1748: 32). Este acontecimiento fue tomado por los romanos como un augurio de prosperidad. Así como el cielo ciñó a Augusto una corona, la Universidad de México, que es el sol de la sabiduría, junto con sus doctores o estrellas, le ofrecería otra a Fernando VI: "preciso era que el sol de la sabiduría mexicana [la universidad] con sus doctorales estrellas se inclinase leal y reverente a formar a su esclarecido real patrono la corona, o círculo hermoseado con la variedad de colores de las ínfulas que denotan las facultades que profesan" (Rodríguez de Arizpe 1748: 33). Quedan establecidas las reglas del juego: el rey es 


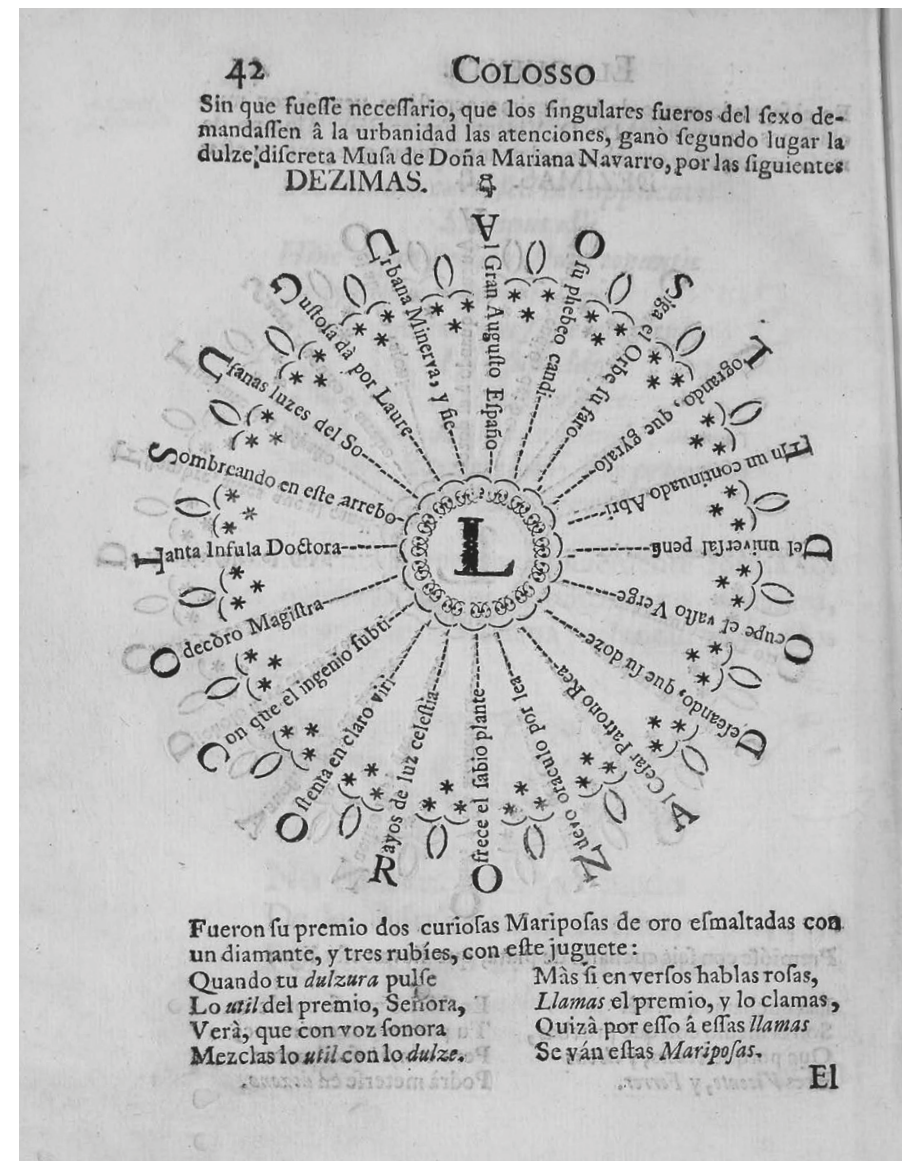

Fig. 4. Décimas acrósticas y forzadas de Mariana Navarro (en Rodríguez de Arizpe 1748: 43).

Augusto; la universidad, el sol; el círculo a su alrededor, las coronas o caligramas; los colores del arcoiris, los diferentes colores de las ínfulas universitarias.

A pesar de que son cuatro los que aparecen en el Coloso elocuente, el mejor caligrama es, a mi ver, el de Mariana Navarro, de quien por desgracia no tenemos dato alguno y cuyo poema obtiene injustamente el segundo lugar. El primer premio se lo lleva Vicente Ferrer Díaz que, sospechosamente, era alumno del secretario del certamen en el Colegio Seminario. Rodríguez de Arizpe afirma que a la poeta se le concedió el premio no como una cortesía hacia su sexo, sino a causa de la suavidad e ingenio de su poema: "sin que fuese necesario que los singulares fueros del sexo demandasen a la urbanidad las atenciones, ganó segundo lugar la dulce, discreta musa de doña Mariana Navarro por las siguientes décimas" (1748: 42):

Al gran Augusto español

Urbana Minerva y fiel

Gustosa da por laurel 
Ufanas luces del sol,

Sombreando en este arrebol

Tanta ínfula doctoral ${ }^{14}$,

O decoro magistral,

Con que el ingenio sutil

Ostenta en claro viril ${ }^{15}$

Rayos de luz celestial.

Ofrece el sabio plantel

Nuevo oráculo por leal

Al César, patrono real,

Deseando que su dosel ${ }^{16}$

Ocupe el vasto vergel

Del universal pensil

En un continuado Abril,

Logrando que, girasol,

Siga el orbe su farol

O su febeo candil.

En la primera de las décimas, la "urbana" y "fiel" "Minerva”, es decir, la cortesana y leal Universidad de México (se le llama Minerva en muchos lugares del Coloso, en el resto de los poemas de esta categoría y en otros certámenes como el Triunfo parténico) da al "gran Augusto español", o sea, a Fernando VI, no una corona de laureles, sino una tejida de "ufanas luces del sol". "Sombreando en este arrebol" es un verso difícil: la poeta parece decir que esa corona la universidad la dará "sombreando" el arrebol de los rayos solares con las ínfulas de doctores y maestros. Puede estar jugando la poeta con el sentido, muy común en la época, de sombra como 'semejanza': la universidad dará la corona a Fernando VI del mismo modo que el sol la ofreció a Augusto. El “ingenio sutil” "ostenta” en esas ínfulas de doctores y maestros universitarios "rayos de luz celestial” como a través del cristal de un "claro viril", que es la universidad misma. Es interesante que la poeta, a quien le estaba vedada la entrada a las aulas universitarias por el hecho de ser mujer, diga que el ingenio emita rayos a través de un viril, que deja ver pero, al mismo tiempo, resguarda aquello que contiene. Mariana Navarro parece contemplar desde fuera el resplandor universitario, pero sin poder formar parte del mismo.

14 Las infulas son ornamento de la vestidura de los pontífices: se trata de dos franjas de tela que cuelgan de la mitra y descienden por la espalda. Por supuesto, los doctores universitarios no se atavían con ínfulas, esa es únicamente la manera en la que el secretario del certamen denominó a la borla, un "botón de seda, oro, plata hilo o lana" que se pone sobre los birretes. Las borlas son "insignia de los graduados de doctores y maestros en las universidades" y sus colores distinguen las distintas facultades de las que estos proceden (Diccionario de Autoridades): los teólogos de blanco, los filósofos de azul, los médicos de amarillo, los doctores en Derecho canónico de verde, los de Derecho civil, de rojo.

15 viril: "vidrio muy claro y transparente que se pone delante de algunas cosas para reservarlas o defenderlas, dejándolas patentes a la vista" (Diccionario de Autoridades).

16 dosel: "adorno honorífico y majestuoso que se compone de uno como cielo de cama puesto en bastidor con cenefas a la parte de adelante y a los dos lados, y una cortina pendiente en la de atrás que cubre la pared o paraje donde se coloca" (Diccionario de Autoridades). 
En la segunda décima, el "sabio plantel”, del mismo modo que el sol aquel arco que significó un buen presagio para el reinado naciente de Augusto, ofrece con estos círculos poéticos un "nuevo oráculo" a su monarca y desea que sus dominios, su "dosel", se extiendan por todo el mundo, el cual, bajo su reinado, experimentará un "continuado abril”, una interminable primavera. El orbe entero seguirá, como Clitie, que enamorada de Febo Apolo terminó por transformarse en girasol, el sol de Fernando VI, su "farol", su "febeo candil"17.

Por este poema, Mariana Navarro se llevó "dos curiosas mariposas de oro esmaltadas con un diamante y tres rubíes". Se acompañaron del siguiente epigrama, en el que se juega con el viejo tópico petrarquista de la mariposa que, incauta, queda cautivada por la llama y en ella encuentra su fin:
Cuando tu dulzura pulse
lo útil del premio, señora, verá que con voz sonora mezclas lo útil con lo dulce. Mas si en versos hablas rosas, llamas el premio y lo clamas; quizá por eso a esas llamas se van estas mariposas (Rodríguez de Arizpe 1748: 42).

La labor del novohispanista, como he dicho, a veces tiene algo de arqueológica. Para llevar a cabo la interpretación de un poema ganador en un certamen poético es necesario reconstruir, en la medida de lo posible, el contexto. El texto es en sí mismo pero también, y sobre todo en casos como en el que aquí nos ha ocupado, en sus circunstancias. Tales circunstancias pueden reconstruirse a través de una lectura cuidadosa de la relación impresa que da cuenta de las peculiaridades del certamen y de los festejos aunados al mismo. Es una pena que la mayoría de estas relaciones no conozcan una edición moderna y que algunas, incluso, hayan permanecido manuscritas por siglos. La edición y difusión de los certámenes literarios novohispanos, los cuales ofrecen una imagen tan nítida de las prácticas literarias de aquellos siglos, es una de las tareas más urgentes de los estudios virreinales.

Lejos han quedado los tiempos en los que esta literatura "de ocasión" era objeto del desprecio generalizado de la crítica. Por mucho tiempo se aseveró que los motivos de los certámenes resultaban despreciables y que la prosa que de ellos daba cuenta era ampulosa hasta el hartazgo. Y ni hablar de los poemas participantes: no faltó quien opinara que "el esfuerzo de los poetastros por remedar los hábitos literarios de la madre patria excedió a sus modelos en las fantasías

17 Celebro que Ramírez (2010) haya llamado la atención sobre este poema pero deploro que su interpretación esté repleta de disparates: afirma que la autora "se proclama a sí misma como la diosa de la inteligencia y las artes"; que el caligrama es también "la rueda de la fortuna", lo que revela "una influencia de Kircher y los arcanos del cosmos"; que esa mano que aparece encima de las décimas, que no es sino una marca de la imprenta para llamar la atención y que aparece en el resto de los caligramas del certamen, es "la mano creadora", la "mano femenina de la autora, quien tiene en ese origen, ese cosmos en sus manos decidiendo la fortuna de todo" (sic). Desde mi punto de vista, la autora debió tomarse la molestia de leer, más que a Julia Kristeva, algunas líneas del Coloso elocuente antes de lanzarse a interpretar el poema de Mariana Navarro. 
ridículas, en la pomposidad, en la pedantería y en otras formas de flatulencia retórica” (Leonard 1974: 214). Gran parte de la poesía del siglo XX y buena parte de la actual nos ha entrenado para la lectura de este tipo de poemas. Nuestra sensibilidad, habituada a los caligramas de Tablada, a los topoemas de Paz, a los experimentos de Ulises Carrión y hasta a los poemojis, no se espanta ya de estos malabares de la lengua. Hay que tomarnos, pues, estos divertimentos virreinales muy en serio, sacudir el polvo de los viejos volúmenes y amontonarnos, entre espejos, jeroglíficos y columnas de fuego, en la premiación de estos poemas delirantes, en la fiesta que aguarda entre las páginas de libros como el Coloso elocuente.

\section{Referencias bibliográficas}

Acevedo, L. (1600). Marial. Discursos morales en las fiestas de la Reina del Cielo, Nuestra Señora. Valladolid: Francisco Fernández de Córdova.

Beristáin de Souza, J. M. (1816). Biblioteca hispanoamericana septentrional. Tomo I. México: Alejandro Valdés.

Góngora, L. (1985). Romances. A. Carreño (Ed.). Madrid: Cátedra.

Gracián, B. (1669). El Criticón. Primera parte, en la primavera de la niñez y en el estío de la juventud. Amberes: Jerónimo y Iuanbaut Verdussen.

Gutiérrez Reyna, J. (2014). Óyeme con los ojos. Poesía visual novohispana. Ilustraciones de Mateo Pizarro. México: Consejo Nacional para la Cultura y las Artes/La Diéresis.

Hernández Fuentes, M. Á. (2014). Mitología en las arquitecturas efímeras del Barroco. In Ma. D. Jiménez,

$\mathrm{M}^{\mathrm{a}}$ del Val Gago, M. Paz, \& V. Enamorado (Eds.), Espacios míticos: Historias verdaderas, historias literarias (pp. 97-130) Madrid: El Jardín de la Voz.

Leonard, I. A. (1974). La época barroca en el México colonial. A. Ezcurdia (Trad.). México: Fondo de Cultura Económica.

Navarro, M. (invierno 2002-2003). A Fernando VI. Décimas acrósticas. Alforja. Revista de Poesía. XXIII: Poesía visual en México, 10.

Pascual Buxó, J. (1959). Arco y certamen en la poesía mexicana colonial (siglo XVII). México: Universidad Veracruzana.

Paz, O. (1972). El arco y la lira. México: Fondo de Cultura Económica.

Picinelli, F. (1687). Mundus symbolicus. Tomo I. Colonia: Hermann Demen.

Plinio, el Viejo (1629). Historia natural. Tomo II. Traducción de Jerónimo de Huerta. Madrid: Juan González.

(1870). Naturalis historice. Volumen V, libros XXXIII-XXXVII. Edición de Crolus Mayhoff. Leipzig: B. G. Teubner.

Ramírez Olivares, A. V. (2010). Mariana Navarro: poesía visual femenina en el siglo XVIII. In E. Cortez, \& G. Kirkpatrick (Eds.), Actas del XXXVIII Congreso Internacional del Instituto Internacional de Literatura Iberoamericana. <http://www.iiligeorgetown2010.com/2/pdf/Ramirez-Olivares.pdf $>$.

Reyes, A. (2007 [1946]). Letras de la Nueva España. México: Fondo de Cultura Económica. 
Rodríguez de Arizpe, P. J. (1748). Coloso elocuente que en la solemne aclamación del augusto monarca de las Españas, don Fernando VI (que Dios prospere) erigió sobre brillantes columnas la reconocida lealtad y fidelísima gratitud de la Imperial y Pontificia Universidad Mexicana, Atenas del Nuevo Mundo. México: Nuevo Rezado de Doña María de Ribera.

Rodríguez Hernández, D. (2014). Texto y fiesta en la literatura novohispana (1650-1700). Prefacio de José Pascual Buxó. México: Universidad Nacional Autónoma de México.

Tenorio, M. L. (2010). Poesía novohispana. Antología. México: El Colegio de México/Fundación para las Letras Mexicanas.

. (2013). El gongorismo en Nueva España. Ensayo de restitución. México: El Colegio de México.

Vigil, J. M. (1893). Poetisas mexicanas (siglos XVI, XVII, XVIII y XIX). Antología formada por encargo de la Junta de Señoras correspondiente de la Exposición de Chicago. México: Secretaría de Fomento. 
